\title{
Behaviour of freshwater snails (Radix balthica) exposed to the pharmaceutical sertraline under simulated predation risk
}

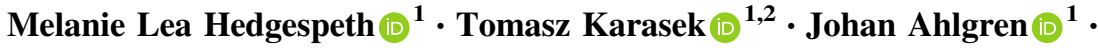 \\ Olof Berglund $^{1} \cdot$ Christer Brönmark ${ }^{1}$
}

Accepted: 15 November 2017 / Published online: 18 January 2018

(C) The Author(s) 2018. This article is an open access publication

\begin{abstract}
Due to their potential for affecting the modulation of behaviour, effects of selective serotonin reuptake inhibitors (SSRIs) in the environment are particularly interesting regarding interspecies interactions and nonconsumptive effects (NCEs) induced by predator cues in prey organisms. We evaluated the effects of sertraline $(0.4$, $40 \mathrm{ng} / \mathrm{L}, 40 \mu \mathrm{g} / \mathrm{L}$ ) over 8 days on activity and habitat choice in the freshwater snail Radix balthica, on snails' boldness in response to mechanical stimulation (simulating predator attack), and their activity/habitat choice in response to chemical cues from predatory fish. We hypothesised that sertraline exposure would detrimentally impact NCEs elicited by predator cues, increasing predation risk. Although there were no effects of sertraline on NCEs, there were observed effects of chemical cue from predatory fish on snail behaviour independent of sertraline exposure. Snails reduced their activity in which the percentage of active snails decreased by almost $50 \%$ after exposure to fish cue. Additionally, snails changed their habitat use by moving away from open (exposed) areas. The general lack of effects of sertraline on snails' activity and other behaviours in this study is interesting considering that other SSRIs have been
\end{abstract}

Electronic supplementary material The online version of this article (https://doi.org/10.1007/s10646-017-1880-6) contains supplementary material, which is available to authorized users.

Melanie Lea Hedgespeth

melanie.hedgespeth@biol.lu.se

1 Aquatic Ecology, Department of Biology, Lund University, Ecology Building, Lund 223 62, Sweden

2 Department of Hydrobiology, Faculty of Biology, Biological and Chemical Research Centre, University of Warsaw, Żwirki i Wigury 101, Warsaw 02-089, Poland shown to induce changes in gastropod behaviour. This raises questions on the modes of action of various SSRIs in gastropods, as well as the potential for a trophic "mismatch" of effects between fish predators and snail prey in aquatic systems.

Keywords Pharmaceuticals - Behavioural toxicology • Freshwater toxicology $\cdot$ Snail $\cdot$ Predation $\cdot$ Boldness

\section{Introduction}

Pharmaceutical residues are increasingly detected in aquatic environments, especially in surface water samples from areas that serve as recipients of wastewater treatment discharges (e.g. Kolpin et al. 2004). Active ingredients of antidepressant pharmaceuticals such as the selective serotonin reuptake inhibitors (SSRIs) have been detected in wastewater recipients within the nanogram- to low microgram-per-liter range (e.g. fluoxetine: $20 \mathrm{ng} / \mathrm{L}$, citalopram: $40 \mathrm{ng} / \mathrm{L}$, venlafaxine: $1000 \mathrm{ng} / \mathrm{L}$, sertraline: $49 \mathrm{ng} / \mathrm{L}$; Schultz and Furlong 2008), and furthermore, these compounds have been shown to affect behaviour in aquatic organisms, mainly fish (reviewed by Brodin et al. 2014). However, aquatic invertebrates including crustaceans and the less-frequently studied molluscs have recently been identified as being particularly sensitive to SSRIs due to low effect concentrations and high bioaccumulation potential (Fong and Ford 2014; Meredith-Williams et al. 2012).

The neurotransmitter serotonin has been identified as a modulator of biological activity in both gastropods and crustaceans. Influence on locomotion (Pavlova 2001; Syed and Winlow 1989), reproductive processes (Diefenbach 
et al. 1998; Manger et al. 1996), and predator vigilance behaviour (Il-Han et al. 2010) has been documented in gastropods, and in crustaceans, effects on reproductive processes (Wongprasert et al. 2006), locomotion (Tain et al. 2006), and social behaviour (Huber and Delago 1998) have been reported. Though the exact mechanisms are still unknown, it is thought that SSRIs are linked to serotonin activity in these invertebrate groups (e.g. Campos et al. 2013). For instance, SSRIs have been shown to affect both reproduction and behaviour in crustaceans (Campos et al. 2012; Guler and Ford 2010), and reproduction in gastropods (Couper and Leise 1996; Nentwig 2007). However to date, comparatively little research on the potential effects of SSRIs on behaviour or locomotion in gastropods have been reported (but see Fong et al. 2015). Because data are particularly scarce regarding aquatic invertebrate exposure to the SSRI sertraline (as opposed to other SSRIs such as fluoxetine), we selected sertraline as the compound of interest for this study.

In recent years, numerous studies have indicated that predator-induced changes in behaviour can have considerable effects in food chains and that these non-consumptive effects (NCEs) can be as strong as or even stronger than the direct, lethal effects of predators (e.g. Bernot and Turner 2001; Werner and Peacor 2003). Thus, there is a need for increased understanding of how freshwater organisms respond behaviourally to the presence of environmental contaminants such as antidepressants in order to be able to predict their ecological consequences in recipient ecosystems. Previous research has indicated that the serotonergic system mediates changes in snail behaviour caused by predators, examined via injection of serotonin antagonists into organisms (Il-Han et al. 2010). Due to their potential for affecting the modulation of behaviour, effects of SSRIs that are found in aquatic systems are particularly interesting with regard to intra- and interspecies interactions and NCEs. Predator-prey interactions would be a suitable interaction to consider in this regard, since pollutant-induced behavioural changes that may seem subtle or go unnoticed in singlespecies systems may nevertheless have profound effects on population and community dynamics in the environment.

To advance environmental risk assessment, ecotoxicity testing has been shifting from the explicit use of acute, highdose exposures for assessing mortality to the inclusion of chronic exposures assessing effects of contaminants on ecologically-relevant life history parameters, and ultimately, population growth rates (Forbes and Calow 2002). However, the use of behavioural endpoints is still uncommon with regard to the ecotoxicity testing of various pharmaceuticals, and endpoints that reveal information on organism interactions all the more so. In particular, studies on aquatic systems have focused on behavioural endpoints regarding organism interactions within exposed vertebrate taxa (e.g. Barry 2014; Brodin et al. 2013; Hedgespeth et al. 2014; Weinberger and Klaper 2014), but so far, relatively few have addressed invertebrates in this sense (but see Brodin et al. 2014; Fong and Ford 2014).

In this study, we evaluated the effects of the SSRI sertraline on the behavioural changes of the freshwater snail Radix balthica in response to chemical cues from predatory fish. These snails occur in a range of habitats: from small, ephemeral ponds and streams to large lakes and rivers; subsequently, they are also exposed to a variety of different predators (e.g. Brönmark 1992; Nyström et al. 1999). In order to reduce vulnerability they have evolved a number of adaptive traits against predation including changes in life history strategies (Brönmark et al. 2012; Crowl and Covich 1990), morphology (DeWitt et al. 2000; Hoverman et al. 2005), and behaviour (Brönmark and Malmqvist 1986; Rundle and Brönmark 2001; Turner 1996). One effective response of freshwater snails to chemical cues emitted by predators is to increase their refuge use, i.e. via hiding under stones or crawling up above the water's surface (Rundle and Brönmark 2001; Turner 1996). Such predator-induced changes in habitat use and activity have further been found to have strong effects on the biomass of periphytic algae, the snails' primary food source (Brönmark 1989), indicating the importance of such NCEs for ecosystem-wide processes.

In recent years it has become increasingly evident that not all individuals respond similarly to an environmental cue; there is large variability among individuals within a species and even within a population (Bolnick et al. 2011). Many studies have demonstrated that individuals show consistent differences in behavioural traits, including aggression (Duckworth 2006), risk-taking (van Oers et al. 2005), activity (Kurvers et al. 2009), and exploration (Minderman et al. 2009). Such individual-level differences in behaviour that are consistent over time and context, known as "animal personalities," have been demonstrated across a wide range of taxa, from mammals to insects (Bell et al. 2009). One of the most commonly-studied aspects of personality is the behavioural variation of organisms along a bold-shy continuum, in which bolder animals have a higher propensity to engage in risky behaviours and shy individuals are consistently more risk-averse and cautious (Wilson et al. 1994). Recent studies have shown that $R$. balthica demonstrate consistent individual variation in boldness (Ahlgren et al. 2015). Hence, we suspect that the potential effects of SSRIs on such behaviours in snails (in terms of altering the mean response or the consistency of the behaviours within individuals) could consequently impact predator-prey interactions, i.e. via the NCEs induced by predators.

We have therefore assessed the effect of sertraline and predator cue exposure on the activity, boldness, and 
avoidance behaviour of the freshwater snail Radix balthica. Snails were exposed to sertraline $(0.4,40 \mathrm{ng} / \mathrm{L}$, or $40 \mu \mathrm{g} / \mathrm{L})$ over 8 days and then subjected to either a simulated, mechanical predator cue or an chemical predator cue from molluscivorous fish (Carassius carassius). Effects on behaviours were assessed as a result of the potential interaction between the two types of stressors, and as a result of sertraline exposure or predator cue alone. Overall, we expected that sertraline exposure would impact the snails' behaviours in response to predator cues in a negative manner, i.e. in a manner that would make them more susceptible to predation in natural systems.

\section{Methods}

\section{Study organisms}

Adult freshwater snails Radix balthica (Lymnaeidae; $1.7 \pm$ $0.55 \mathrm{~cm}$ length) were collected from ponds located in areas that are not directly impacted by wastewater effluent in the vicinity of Lund, southern Sweden. They were allowed to acclimate to $16: 8 \mathrm{~h}$ light:dark, $18^{\circ} \mathrm{C}$ conditions (similar to environmental conditions), held in dechlorinated tap water, and fed ad libitum with rabbit chow three times per week for 14 days prior to the experiment. Two molluscivorous crucian carp (Carassius carassius, $\sim 10 \mathrm{~cm}$ body length) were collected by trap-netting in a pond in the University Park, Lund and held in an aerated $100 \mathrm{~L}$ aquarium under the same conditions as the snails for approximately 2 months prior to the experiment. The carp were fed snails ( $R$. balthica and Lymnaea stagnalis) three times per week during holding, occasionally supplemented with rabbit chow, and fresh, dechlorinated tap water was added weekly (approximately $1 / 4$ change; water was not changed directly prior to the experiment). They were fed ten crushed $R$. balthica $\sim 4 \mathrm{~h}$ prior to collection of water from the aquarium for use as predator cue in trials on snail behaviour, as predators that have fed on conspecifics elicit stronger behavioural responses in prey compared to unfed predators (Turner et al. 2006).

\section{Chemical exposure and setup}

Stock solutions of sertraline hydrochloride (CAS \#7955997-0, Toronto Research Chemicals Inc.) dissolved in 100\% dimethyl sulfoxide (DMSO) were prepared via dilution series. Though we were unable to directly measure exposure medium at the time of the experiment, analysis of the stock solution confirmed the presence of sertraline-a $10 \times$ dilution of the highest stock concentration was analysed (nominal: $2.0 \mathrm{mg} / \mathrm{L}$; measured: $2.2 \mathrm{mg} / \mathrm{L}$ ) using a Xevo $\mathrm{G} 2$ Q-TOF (Waters, Sweden) connected to an Acquity UPLC system (Waters, Sweden) according to the method by Boström et al. (2016). These were spiked into $2 \mathrm{~L}$ of dechlorinated tap water $(\mathrm{pH}: 8.1 \pm 0.2)$ resulting in nominal exposure concentrations of $0.4,40 \mathrm{ng} / \mathrm{L}$, or $40 \mu \mathrm{g} / \mathrm{L}$ sertraline, along with a solvent control treatment. This resulted in a final solvent concentration of $0.002 \% \mathrm{v}-\mathrm{v}$ DMSO: $\mathrm{H}_{2} \mathrm{O}$ in all exposure treatments, which is both below OECD's recommendations for maximum solvent concentration and is the volume recommended by Hutchinson et al. (2006).

The experiment was performed as a single, static sertraline exposure in $5 \mathrm{~L}$ glass containers with $2 \mathrm{~L}$ of exposure medium and 5 containers per treatment concentration. Additionally, a $10 \times 10 \mathrm{~cm}$ ceramic tile was placed into each container, raised $12 \mathrm{~mm}$ from the bottom with rubber legs to provide potential refuge for the snails for behavioural assays (see following section). On Day 0 of the exposure, five snails were randomly added to each container (100 snails total). The total duration of chemical exposure was 8 days, during which snails were fed three times with rabbit chow ad libitum. Water was neither changed nor aerated due to the snails being air-breathing and containers were not cleaned during the exposure to avoid any potential removal of sertraline from the system. Based on data from our lab where no significant abiotic degradation of sertraline in water was recorded over 35 days (Boström et al. 2016), and literature data reporting limited biodegradation even in sewage sludge (Styrishave et al. 2011), sertraline was not expected to undergo significant degradation over the 8-day exposure period in our study.

\section{Behavioural trials}

Prior to Day 0 of the exposure, snails were individually tagged and assayed twice during the acclimation period (i.e. at the ends of the first and second weeks directly prior to the experiment) for preliminary boldness scores, using the method described by Ahlgren and coauthors (2015). In short, individuals were placed into a petri dish containing clean water and after a $15 \mathrm{~min}$ acclimation period, they were gently tapped on the shell with a pipet tip. After full retraction into the shell, each snail was timed for the reemergence of both antennae from the shell, with an upper time limit of $180 \mathrm{~s}$. On Day 7 of exposure, this assay was repeated to assess post-exposure boldness, during which snails were placed in a petri dish containing treatment water from their respective containers and after which snails were placed back into their respective exposure containers.

During Days 1-7 of the exposure, activity and location of individuals within the containers were noted three times daily ( 11:00, 13:00, and 15:00). Any dead individuals were immediately removed from containers and this information was recorded. Activity was assigned as binary score based on the movement, or lack thereof, of snails at the time 
of observation, resulting in a percentage score per container. Location was scored as one of three possibilities - under the ceramic tile in the bottom of the container: "under tile;" climbed to or above the surface of the water: "surface;" or in the open: "open" (this included snails that were freely floating, those crawling on the sides of the container but below the water's surface, and those on the surface of the ceramic tile).

On Day 8 of the experiment, snails were assayed for activity and location as previously described to serve as a control prior to the addition of predator cue. Immediately afterward, $0.1 \mathrm{~L}$ of predator cue (water taken directly from the aquarium containing carp previously fed with snails) was added to each treatment container. After $20 \mathrm{~min}$, snails were again assayed to determine activity and location in the presence of the fish cue (as established in the method by Ahlgren and Brönmark 2012). Because Ahlgren and Brönmark determined that water containing carp cue elicits predator-induced behavioural changes in snails (2012), and fish cue was 'produced' in the same way in both experiments, chemistry parameters of water containing cue were not measured.

\section{Statistical analyses}

All statistical analyses were carried out using $\mathrm{R}$ version 3.1.0 (2014). Data that did not meet the parametric assumptions of normality and homoscedasticity were transformed if necessary, and ranks were used in cases for which parametric assumptions were not met after transformation. Mauchly's Test for sphericity was also used for repeated measures analyses. For analyses on data regarding habitat choice (i.e. the three possible locations of snails), $p$ values were adjusted using Bonferroni correction.

For activity and location data (Days 1-7), only the snails in the control treatment were analysed to determine whether the time of day the observations were taken had an effect (one-way ANOVA; factor: time of day, block: day nested within time). There was no statistically significant effect of time of day on activity or locations (Activity $45 \pm 32 \%$, $F_{2,16}=0.0048$; Locations: in open $63 \pm 28 \%, F_{2,16}=$ 0.062 ; at surface $28 \pm 29 \%, F_{2,16}=0.090$; under tile $8.3 \pm$ $13 \%, F_{2,16}=0.31$; adjusted $p>0.1$ in all cases), so further statistical analyses on these endpoints for Days 1-7 used the 15:00 data only. The percentage of active snails and percentages observed in each location over the 7-day exposure were analysed using a two-way repeated measures ANOVAs (factors: sertraline treatment $\times$ day; within subjects error: day nested within container).

For Day 8 behavioural data, we assessed the effects of sertraline treatment without and with predator cue on snail activity and locations using $2 \times 2$ mixed factorial ANOVAs with repeated measures on cue (factors: sertraline treatment $\times$ cue; within subjects factor: cue nested within container). For those analyses in which interaction terms were not significant, the interaction term was removed to examine main effects of sertraline and cue only.

To test for pre-exposure, individual consistency in boldness, we used Spearman's rank correlation on the reemergence times from the shell. Post-exposure boldness scores (Day 7) and the relative percent changes in individual boldness scores from Day 0 to Day 7 were both analysed using one-way ANOVAs (factor: sertraline treatment; within subjects factor: individual snails nested within container).

\section{Results}

\section{Effects of sertraline on $R$. balthica behaviour}

Mortality of snails at the end of the experiment was assessed using a GLM (Poisson distribution with log link), indicating no significant effect of sertraline treatment on mortality $(24 \pm 17 \%$ in the control; sertraline coefficient $=$ $0.000013, \mathrm{SE}=0.000010, z=1.3, p>0.1)$. The mean percentage of active snails ranged between 35 and $47 \%$ throughout the exposure period, but there was no interaction between time and treatment using a significance threshold of $\alpha=0.05\left(F_{18,96}=1.6, p=0.088\right.$; Supplementary material Fig. S1). Further, there was no main effect of sertraline on snail activity $\left(F_{3,16}=0.29, p>0.1\right)$. Likewise, there was no significant effect on sertraline on snail location during the experiment (Supplementary material Fig. S2; in open $F_{3,16}=1.5$, at surface $F_{3,16}=0.74$, under tile $F_{3,16}=0.66$, adjusted $p>0.1$ in all cases).

\section{Effects of sertraline on $\boldsymbol{R}$. balthica behaviour when exposed to predator cue}

The addition of a fish predator cue at Day 8 had a significant effect on both activity and location of the snails in all sertraline treatments. The percentage of active snails decreased from a mean of $48 \%$ in all treatments to $26 \%$ after addition of the cue (Fig. 1; $F_{1,19}=5.0, p=0.038$ ). However, there was no effect of sertraline on activity before or after the addition of chemical cue $\left(F_{3,16}=0.74, p>0.1\right)$ and no interaction between the two $\left(F_{3,16}=0.17, p>0.1\right)$. Predator cue also had a significant effect on the use of open habitats (Fig. 2a; $F_{1,19}=11$, adjusted $p=0.011$ ) for which the proportion of snails in open habitat decreased from $62 \%$ to $37 \%$, but there was no significant effect of sertraline and no interaction effect $\left(F_{3,16}=1.4, F_{3,16}=1.1\right.$, respectively, $p>$ 0.1 in both cases). With regard to refuge-seeking behaviour, there was neither a significant effect of predator cue on proportion of snails at/above the surface (Fig. 2b; $F_{1,19}=$ 


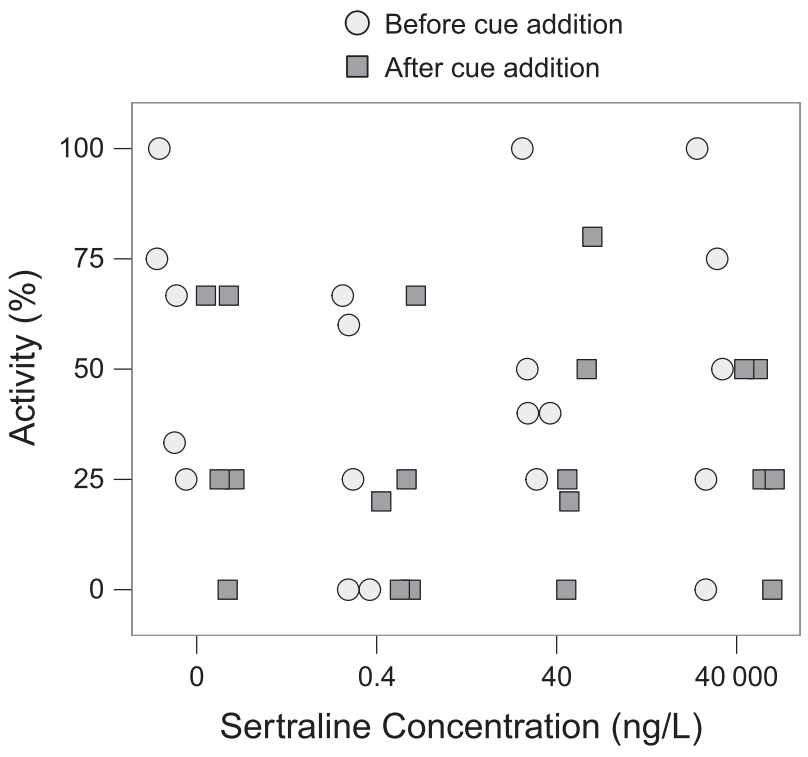

Fig. 1 Percentage of active snails in all treatments on Day 8 of sertraline exposure before (light grey circles; overall mean 48\%) and after (dark grey squares; overall mean 26\%) the addition of chemical cues from the fish predator Carassius carassius, with no effect of sertraline treatment $(p>0.1)$. There was a significant effect of cue overall ( $p=$ 0.038 ; not indicated in the figure)

4.9 , adjusted $p>0.1)$, nor was there a significant effect of sertraline $\left(F_{3,16}=3.7\right.$, adjusted $\left.p>0.1\right)$. There was also no interaction effect between the two stressors $\left(F_{3,16}=0.59\right.$, adjusted $p>0.1$ ). The proportion of snails hiding under tiles increased approximately four-fold from $4 \%$ to $16 \%$ after addition of the cue (Fig. 2c; $F_{1,19}=5.39$, adjusted $p=$ 0.096), though this was not statistically significant at $\alpha=$ 0.05 . There was no effect of sertraline $\left(F_{3,16}=0.49\right.$, adjusted $p>0.1)$ and no interaction between the two stressors $\left(F_{3,16}=0.93\right.$, adjusted $\left.p>0.1\right)$.

\section{Boldness}

Snail boldness (time to re-emergence) showed high individual consistency between trials (Spearman's $\rho=0.84, p<$ 0.001 ), although over time snails became bolder on average, indicated by the slopes of fit for each treatment being $<1$ (i.e. lower scores $=$ less time to emerge from shell; Fig. 3). Sertraline exposure did not affect post-exposure boldness scores at Day $7\left(F_{3,16}=1.1, p>0.1\right)$ nor the relative changes in boldness scores, i.e. pre- to post-exposure $\left(F_{3,16}\right.$ $=0.73, p>0.1$ ).

\section{Discussion}

We did not detect consistent, dose-response related changes in activity pattern or habitat use of the freshwater snail $R$. balthica when exposed to the antidepressant sertraline over
O Before cue addition

$\square$ After cue addition
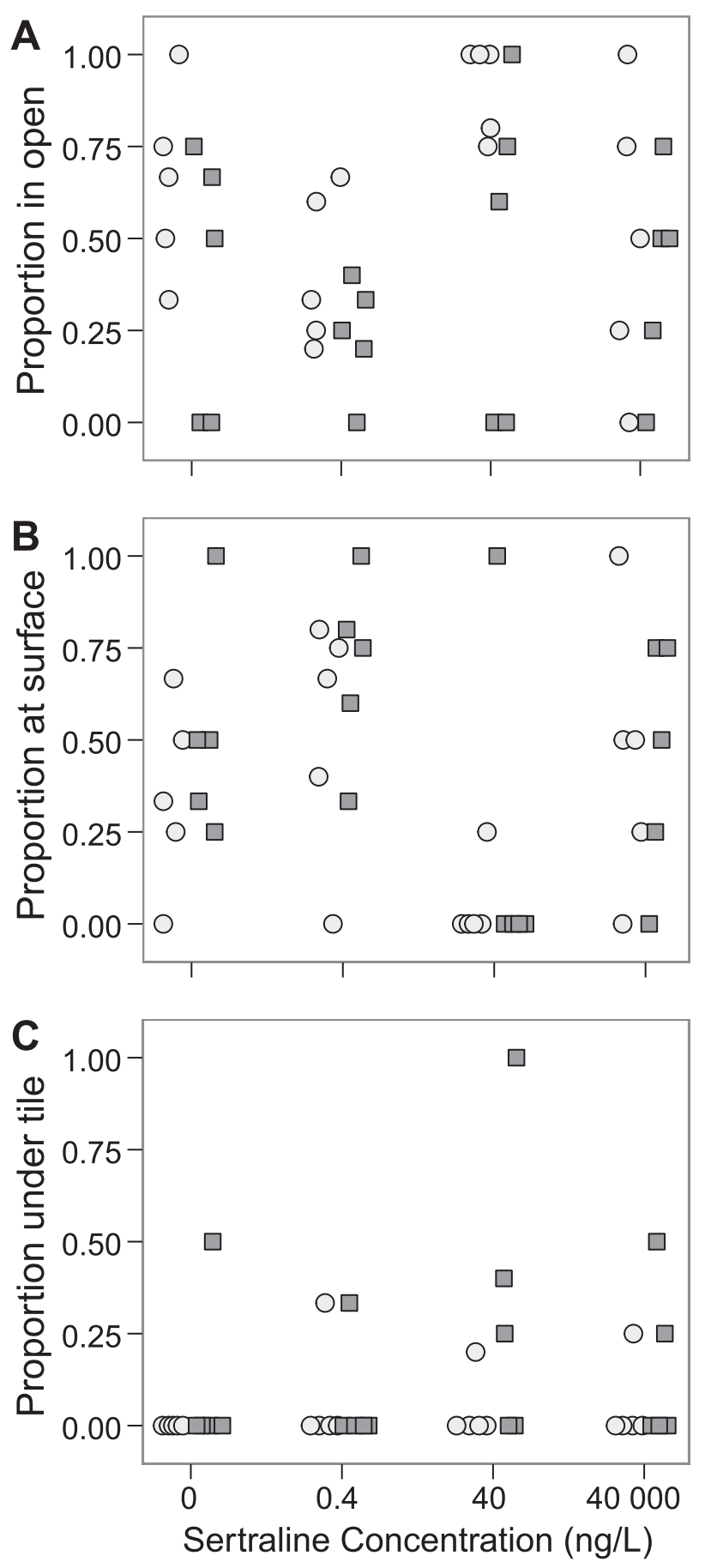

Fig. 2 Proportion of snails in all treatments on Day 8 of sertraline exposure before (light grey circles) and after (dark grey squares) the addition of chemical cues from the fish predator Carassius carassius, based upon location in containers indicative of habitat choice: $\mathbf{a}$ in the open (62 and $37 \%$ before and after cue, respectively, adjusted $p=$ $0.011)$; b at/above the surface of the water (34\% before and $47 \%$ after cue addition, adjusted $p>0.1$ ); and $\mathbf{c}$ underneath the tile ( $4 \%$ before and $16 \%$ after cue addition, adjusted $p=0.096$ ). There were no significant effects of sertraline nor interaction effects of sertraline $\times$ cue for any of the locations (adjusted $p>0.1$ in all cases) 


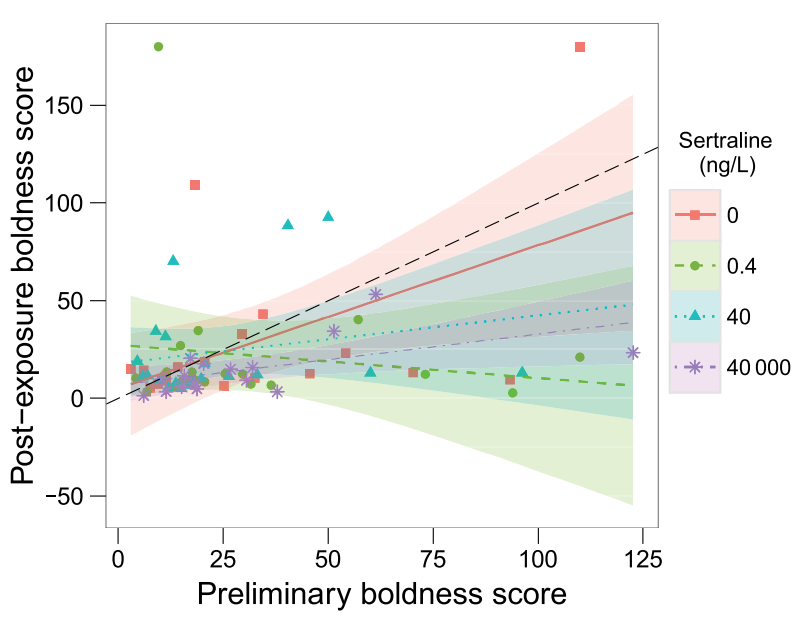

Fig. 3 Data on the individual snails' mean preliminary boldness scores (mean based upon 2 assays per snail before sertraline exposure; $\mathrm{x}$-axis) vs. post-exposure boldness scores (assayed 1 time per snail on Day 7 of sertraline exposure; y-axis). Boldness scores indicate the amount of time (s) taken to re-emerge from the shell after mechanical stimulation (lower scores = bolder snails). Linear fits are plotted for each sertraline treatment (shading indicates the $95 \% \mathrm{CI}$ ) and the dashed, black line is the line of identity, indicating slope $=1$ (i.e. no change in boldness score before and after sertraline exposure)

the exposure period. There was an indication of an interaction effect of sertraline and time on snail activity throughout Days 1 to 7 of exposure ( $p=0.088$; Supplementary material Fig. S1). Exposure to the two highest treatment concentrations may have reduced activity compared to the control between Days 3 and 5, though overall trends in effects of sertraline over time or across concentrations were not convincing. Hunger state in a different species of snail (Lymnaea stagnalis) of the same family as $R$. balthica has been shown to affect locomotion, in which recently-fed snails moved slower than hungry snails (Sidorov 2006). The lack of significant effects of time of day on snail activity in control animals (i.e. described in the Methods section under "Statistical Analyses") makes it unlikely that feeding the snails every other day during the exposure period in our study affected the results of the activity measurements.

To our knowledge, there are no reports on organismlevel effects of sertraline in gastropods. Sertraline generally has a high detection frequency in aquatic environments in Europe and North America (reviewed by Silva et al. 2012), with surface water concentrations measured up to $49 \mathrm{ng} / \mathrm{L}$ (Schultz and Furlong 2008) and wastewater effluents up to $120 \mathrm{ng} / \mathrm{L}$ (Nagarnaik et al. 2011). The highest sertraline concentration used in our study, $40 \mu \mathrm{g} / \mathrm{L}$, was chosen because it is within the range shown to affect behaviour in fish (Hedgespeth et al. 2014; Valenti et al. 2012) and life history parameters in crustaceans (Henry et al. 2004; Lamichhane et al. 2014). Published studies on bioconcentration and bioaccumulation of pharmaceuticals in snails are scarce; the only report of a BAF for sertraline in snails found in the literature was $990 \mathrm{~L} / \mathrm{kg}$ for snails from the family Planorbidae (Du et al. 2015). However, if R. balthica indeed displays a similar BAF for sertraline, we can assume that snails likely took up sertraline present in exposure media in our experiment.

For the more frequently studied SSRI fluoxetine, effect concentrations on reproductive parameters in gastropods have been reported in the low to high $\mu \mathrm{g} / \mathrm{L}$ range (Nentwig 2007; Péry et al. 2008). The general lack of effects of sertraline on snails' activity and other behaviours in this study is interesting considering that other SSRIs have been shown to induce changes in gastropod behaviour. For example, recent studies on locomotion after fluoxetine exposure showed effect concentrations of $20 \mu \mathrm{g} / \mathrm{L}$ for movement and burrowing behaviour in freshwater mussels (Hazelton et al. 2014), and of 40-345 $\mu \mathrm{g} / \mathrm{L}$ for foot detachment and locomotion in marine snails (Fong et al. 2015; Fong and Molnar 2013). When considering human pharmacological data, one possible reason for this discrepancy might be that fluoxetine's primary metabolite, norfluoxetine, is an equally effective SSRI whereas sertraline's is inactive (van Harten 1993); additionally, though the two SSRIs have the same primary mechanism of action, fluoxetine's binding is less selective for serotonin receptors (with more potential for dopamine and norepinephrine receptor interactions) compared with sertraline (Bymaster et al. 2002). The metabolism and receptor binding selectivities of various SSRIs in gastropods have not yet been assessed in depth and would help to elucidate apparent differences in sensitivity to different compounds. Interestingly, the reported toxic potency of sertraline to crustaceans has been higher than that of fluoxetine (Christensen et al. 2007; Henry et al. 2004); whether the opposite is true for gastropods still remains to be determined. Interspecies differences in sensitivity can vary by several orders of magnitude for SSRIs and are dependent upon the endpoints studied (e.g. reviewed by Silva et al. 2015); thus generalisations for both toxic levels and ranking across species should be made with caution.

We expected that sertraline would modulate the snails' behavioural responses to predator cues (NCEs of the predators). Previous research has found that the enhanced memory formation and predator vigilance behaviour in Lymnaea stagnalis caused by predator cues via activation of the serotonergic system were blocked after serotonin receptor antagonists were injected (Il-Han et al. 2010). Regarding SSRIs specifically, a study on fluoxetine found that exposure to $3 \mu \mathrm{g} / \mathrm{L}$ eliminated hiding behaviour in tadpoles exposed to predator cues (Barry 2014), crayfish exposed to 2 and $500 \mu \mathrm{g} / \mathrm{L}$ fluoxetine demonstrated reduced locomotion (Tierney et al. 2016), and crabs exposed to 25 $\mathrm{mg} / \mathrm{L}$ fluoxetine reduced the amount of time spent in a dark zone, indicating reduced anxiety-like behaviour (Hamilton 
et al. 2016). However, the observed effect of chemical cue from predatory fish on snail behaviour was independent of sertraline exposure in our study. When aquatic wastewater recipients contain molluscivorous fish, snails in these habitats are exposed to predators and chemicals like sertraline simultaneously. Our study organism $R$. balthica has been shown to reduce its activity and increase refuge use by either hiding under stones or climbing above the water surface as a response to chemical cues from predatory fish (Brönmark et al. 2012; Rundle and Brönmark 2001). In our study, fewer snails were present in the open after the addition of the chemical predator cue; snails responded to the cue by hiding underneath the tile and moving to or above the water's surface (Fig. 2). Also, 20 min after the cue was added snails decreased their activity in all treatments by approximately $50 \%$ (Fig. 1). Sertraline did not significantly interfere with either refuge use (surface and under tile) or activity-i.e., at these concentrations and within the timescale of the experiment, sertraline did not modify the NCEs induced by the predator cue.

As behavioural traits including aggression and social dominance are linked to serotonin levels in invertebrates (Kravitz and Huber 2003), we expected that SSRIs could also affect individual consistency in boldness. We predicted that sertraline exposure would alter boldness in $R$. balthica and consequently affect the snails' predation risk by fish; however, we found no evidence for such effects in the current study. When studying the effects of biotic and abiotic stressors on prey behaviours, researchers typically focus on the "average" behaviours in a population even though there can be a large amount of variability among individuals in their behavioural responses to the stressor. This type of inter-individual variation in behavioural traits can be consistent over time and contexts within an individual, including the propensity to take risks (e.g. bold/shy continuum Bell et al. 2009; Wilson et al. 1994). This has also been observed in R. balthica for which shells are used as a refuge from predation and thus, relatively short emergence time from the shell could be considered a measure of boldness (Ahlgren et al. 2015). Further, such interindividual differences in personality can play a key role in predator-prey interactions; for example, boldness can affect an individual snail's probability of mortality by predation (Ahlgren J, et al., unpublished data). Similarly to Ahlgren et al. (2015), we found a high degree of consistency in time to emerge from the shell after mechanical stimulation meant to simulate potential predation risk, indicating that the assay is an effective means of measuring risk-taking behaviour in snails.

Regarding the mortality of the snails $(24 \pm 17 \%$ in the control treatment), our previous experience in working with $R$. balthica indicates that the level of mortality seen in this experiment is not unusually high. For example, a study published by Hallgren et al. (2012) demonstrated a mortality of $R$. balthica at $57 \pm 15 \%$ in the control. The same study found a mortality ranging from $33-82 \%$ in various treatments of ethinylestradiol exposure with no significant difference between treatments. A separate study has also reported a mortality of $38 \%$ for $R$. balthica serving as experimental controls, i.e. snails uninfected with a parasite (Caron et al. 2007).

Though our study did not detect significant effects of sertraline resulting in impacts on snails' predation risk, we suggest that such approaches including multiple stressors are nonetheless valuable to understanding ecological impacts of chemical contaminants. The uncertainties associated with the extrapolation of toxicity data from simplified, controlled laboratory studies used to predict risks in complex environments are profound. The sensitivity and susceptibility of organisms to chemicals can be affected by additional environmental or internal factors influencing bioavailability, toxicokinetics, or tolerance (Holmstrup et al. 2010). Chemical effects may therefore go unnoticed under optimal conditions and may only be expressed or observable when additional stress to the organism is present; for instance, studies on aquatic crustaceans have shown that exposure to multiple biotic and abiotic stressors can, as a result, lead to non-additive effects (Coors and De Meester 2008). To enable more realistic exposure and effect scenarios for organisms and ecosystems, researchers should continue to integrate multiple, natural and anthropogenic stressors in ecotoxicity testing (e.g. exposure to additional chemical contaminants, changes in abiotic factors like temperature or $\mathrm{pH}$, or exposure to predators and predation risk).

\section{Conclusions}

The general lack of effects of sertraline on snails' activity and other behaviours in this study is interesting considering that other SSRIs have been shown to induce changes in gastropod locomotion (Fong et al. 2015). Additionally, sertraline exposure did not appear to impact NCEs induced by predator cues in R. balthica. Regarding the predator/prey system of this study, we suggest that predatory fish may be more sensitive to SSRIs than their snail prey. SSRIs have been shown to affect fish predator/prey behaviour at 0.01-4 $\mu \mathrm{g} / \mathrm{L}$ concentrations (Dzieweczynski et al. 2016; Hedgespeth et al. 2014; Stanley et al. 2007; Valenti et al. 2012; Weinberger and Klaper 2014). Thus, given our findings and the current literature data on fish, we would predict a "trophic sensitivity mismatch" where predators may be affected at concentrations at which the anti-predator responses of gastropod prey remain unaffected. Additional experiments allowing for the predation of snails by fish 
would aid in determining whether the lack of sertraline's impacts on NCEs also agrees with actual predation risk, as well as the subsequent influence thereof on freshwater communities.

Funding This study was financially supported in part by the Swedish Research Council (grant number 621-2009-3831).

\section{Compliance with ethical standards}

Conflict of interest The authors declare that they have no competing interests.

Ethical approval All procedures performed involving animals were in accordance with the ethical standards of the institution at which the study was conducted. Fish from which chemical cue was collected were held in the laboratory via approval from the Malmö-Lunds Animal Research Ethics Committee (permit M36-14). This article does not contain any studies with human participants performed by any of the authors.

Open Access This article is distributed under the terms of the Creative Commons Attribution 4.0 International License (http://crea tivecommons.org/licenses/by/4.0/), which permits unrestricted use, distribution, and reproduction in any medium, provided you give appropriate credit to the original author(s) and the source, provide a link to the Creative Commons license, and indicate if changes were made.

\section{References}

Ahlgren J, Brönmark C (2012) Fleeing towards death-leech-induced behavioural defences increase freshwater snail susceptibility to predatory fish. Oikos 121:1501-1506. https://doi.org/10.1111/j. 1600-0706.2012.20420.x

Ahlgren J, Chapman BB, Nilsson PA, Brönmark C (2015) Individual boldness is linked to protective shell shape in aquatic snails. Biol Lett 11:20150029. https://doi.org/10.1098/rsbl.2015.0029

Barry MJ (2014) Fluoxetine inhibits predator avoidance behavior in tadpoles. Toxicol Environ Chem 96:641-649. https://doi.org/10. 1080/02772248.2014.966713

Bell AM, Hankison SJ, Laskowski KL (2009) The repeatability of behaviour: a meta-analysis. Anim Behav 77:771-783

Bernot R, Turner A (2001) Predator identity and trait-mediated indirect effects in a littoral food web. Oecologia 129:139-146. https://doi. org/10.1007/s004420100705

Bolnick DI et al. (2011) Why intraspecific trait variation matters in community ecology. Trends Ecol Evol 26:183-192. https://doi. org/10.1016/j.tree.2011.01.009

Boström ML, Ugge G, Jönsson JÅ, Berglund O (2016) Bioaccumulation and trophodynamics of the antidepressants sertraline and fluoxetine in laboratory-constructed, three-level aquatic food chains Environ Toxicol Chem 36:1029-1037. https://doi.org/10. 1002/etc.3637

Brodin T, Fick J, Jonsson M, Klaminder J (2013) Dilute concentrations of a psychiatric drug alter behavior of fish from natural populations. Science 339:814-815. https://doi.org/10.1126/ science. 1226850

Brodin T, Piovano S, Fick J, Klaminder J, Heynen M, Jonsson M (2014) Ecological effects of pharmaceuticals in aquatic systems —impacts through behavioural alterations. Philos Trans R Soc B 369:1-10. https://doi.org/10.1098/rstb.2013.0580

Brönmark C (1989) Interactions between epiphytes, macrophytes and freshwater snails: a review. J Mollus Stud 55:299-311. https:// doi.org/10.1093/mollus/55.2.299

Brönmark C (1992) Leech predation on juvenile freshwater snails: effects of size, species and substrate. Oecologia 91:526-529. https://doi.org/10.1007/bf00650326

Brönmark C, Lakowitz T, Nilsson PA, Ahlgren J, Lennartsdotter C, Hollander J (2012) Costs of inducible defence along a resource gradient. PLoS ONE 7:e30467. https://doi.org/10.1371/journal. pone. 0030467

Brönmark C, Malmqvist B (1986) Interactions between the leech Glossiphonia complanata and its gastropod prey. Oecologia 69:268-276. https://doi.org/10.1007/bf00377633

Bymaster F et al. (2002) Fluoxetine, but not other selective serotonin uptake inhibitors, increases norepinephrine and dopamine extracellular levels in prefrontal cortex. Psychopharmacology 160:353-361. https://doi.org/10.1007/s00213-001-0986-x

Campos B et al. (2013) Identification of metabolic pathways in Daphnia magna explaining hormetic effects of selective serotonin reuptake inhibitors and 4-nonylphenol using transcriptomic and phenotypic responses. Environ Sci Technol 47:9434-9443. https://doi.org/10.1021/es4012299

Campos B, Piña B, Barata CC (2012) Mechanisms of action of selective serotonin reuptake inhibitors in Daphnia magna. Environ Sci Technol 46:2943-2950. https://doi.org/10.1021/ es203157f

Caron Y, Lasri S, Losson B (2007) Fasciola hepatica: an assessment on the vectorial capacity of Radix labiata and $R$. balthica commonly found in Belgium. Vet Parasitol 149:95-103. https://doi. org/10.1016/j.vetpar.2007.07.012

Christensen AM, Faaborg-Andersen S, Flemming I, Baun A (2007) Mixture and single-substance toxicity of selective serotonin reuptake inhibitors toward algae and crustaceans. Environ Toxicol Chem 26:85-91. https://doi.org/10.1897/06-219r.1

Coors A, De Meester L (2008) Synergistic, antagonistic and additive effects of multiple stressors: predation threat, parasitism and pesticide exposure in Daphnia magna. J Appl Ecol 45:1820-1828. https://doi.org/10.1111/j.1365-2664.2008.01566. $\mathrm{X}$

Couper JM, Leise EM (1996) Serotonin injections induce metamorphosis in larvae of the gastropod mollusc Ilyanassa obsoleta. Biol Bull 191:178-186

Crowl TA, Covich AP (1990) Predator-induced life-history shifts in a freshwater snail. Science 247:949-951. https://doi.org/10.1126/ science.247.4945.949

DeWitt T, Robinson B, Sloan Wilson D (2000) Functional diversity among predators of a freshwater snail imposes an adaptive tradeoff for shell morphology. Evol Ecol Res 2:129-148

Diefenbach T, Koss R, Goldberg J (1998) Early development of an identified serotonergic neuron in Helisoma trivolvis embryos: serotonin expression, de-expression, and uptake. J Neurobiol 34:361-376. PMID: 9514525

Du B, Haddad SP, Scott WC, Chambliss CK, Brooks BW (2015) Pharmaceutical bioaccumulation by periphyton and snails in an effluent-dependent stream during an extreme drought. Chemosphere 119:927-934. https://doi.org/10.1016/j.chemosphere. 2014.08.044

Duckworth RA (2006) Behavioral correlations across breeding contexts provide a mechanism for a cost of aggression. Behav Ecol 17:1011-1019. https://doi.org/10.1093/beheco/ar1035

Dzieweczynski TL, Kane JL, Campbell BA, Lavin LE (2016) Fluoxetine exposure impacts boldness in female Siamese fighting fish. Betta splendens Ecotoxicol 25:69-79. https://doi.org/10. 1007/s10646-015-1568-8 
Fong PP, Bury TB, Dworkin-Brodsky AD, Jasion CM, Kell RC (2015) The antidepressants venlafaxine ("Effexor") and fluoxetine ("Prozac") produce different effects on locomotion in two species of marine snail, the oyster drill (Urosalpinx cinerea) and the starsnail (Lithopoma americanum). Mar Environ Res 103:89-94. https://doi.org/10.1016/j.marenvres.2014.11.010

Fong PP, Ford AT (2014) The biological effects of antidepressants on the molluscs and crustaceans: a review. Aquat Toxicol 151:4-13. https://doi.org/10.1016/j.aquatox.2013.12.003

Fong PP, Molnar N (2013) Antidepressants cause foot detachment from substrate in five species of marine snail. Mar Environ Res 84:24-30. https://doi.org/10.1016/j.marenvres.2012.11.004

Forbes VE, Calow P (2002) Population growth rate as a basis for ecological risk assessment of toxic chemicals. Philos Trans R Soc Lond B 357:1299-1306. https://doi.org/10.1098/rstb.2002.1129

Guler Y, Ford AT (2010) Anti-depressants make amphipods see the light. Aquat Toxicol 99:397-404. https://doi.org/10.1016/j.aqua tox.2010.05.019

Hallgren P, Sorita Z, Berglund O, Persson A (2012) Effects of $17 \alpha-$ ethinylestradiol on individual life-history parameters and estimated population growth rates of the freshwater gastropods Radix balthica and Bithynia tentaculata. Ecotoxicology 21:803-810. https://doi.org/10.1007/s10646-011-0841-8

Hamilton TJ, Kwan GT, Gallup J, Tresguerres M (2016) Acute fluoxetine exposure alters crab anxiety-like behaviour, but not aggressiveness. Sci Rep 6:19850. https://doi.org/10.1038/ srep19850

Hazelton PD, Du B, Haddad SP, Fritts AK, Chambliss CK, Brooks BW, Bringolf RB (2014) Chronic fluoxetine exposure alters movement and burrowing in adult freshwater mussels. Aquat Toxicol 151:27-35. https://doi.org/10.1016/j.aquatox.2013.12. 019

Hedgespeth ML, Nilsson PA, Berglund O (2014) Ecological implications of altered fish foraging after exposure to an antidepressant pharmaceutical. Aquat Toxicol 151:84-87. https://doi.org/10. 1016/j.aquatox.2013.12.011

Henry TB, Kwon J-W, Armbrust KL, Black MC (2004) Acute and chronic toxicity of five selective serotonin reuptake inhibitors in Ceriodaphnia dubia. Environ Toxicol Chem 23:2229-2233. https://doi.org/10.1897/03-278

Holmstrup $\mathrm{M}$ et al. (2010) Interactions between effects of environmental chemicals and natural stressors: a review. Sci Total Environ 408:3746-3762. https://doi.org/10.1016/j.scitotenv. 2009.10.067

Hoverman JT, Auld JR, Relyea RA (2005) Putting prey back together again: integrating predator-induced behavior, morphology, and life history. Oecologia 144:481-491. https://doi.org/10.1007/ s00442-005-0082-8

Huber R, Delago A (1998) Serotonin alters decisions to withdraw in fighting crayfish, Astacus astacus: the motivational concept revisited. J Comp Physiol A 182:573-583. https://doi.org/10. 1007/s003590050204

Hutchinson TH, Shillabeer N, Winter MJ, Pickford DB (2006) Acute and chronic effects of carrier solvents in aquatic organisms: a critical review. Aquat Toxicol 76:69-92. https://doi.org/10.1016/ j.aquatox.2005.09.008

Il-Han J, Janes T, Lukowiak K (2010) The role of serotonin in the enhancement of long-term memory resulting from predator detection in Lymnaea. J Exp Biol 213:3603-3614. https://doi.org/ 10.1242/jeb.048256

Kolpin DW, Skopec M, Meyer MT, Furlong ET, Zaugg SD (2004) Urban contribution of pharmaceuticals and other organic wastewater contaminants to streams during differing flow conditions. Sci Total Environ 328:119-130. https://doi.org/10.1016/j. scitotenv.2004.01.015
Kravitz EA, Huber R (2003) Aggression in invertebrates. Curr Opin Neurobiol 13:736-743. https://doi.org/10.1016/j.conb.2003.10. 003

Kurvers RHJM, Eijkelenkamp B, van Oers K, van Lith B, van Wieren SE, Ydenberg RC, Prins HHT (2009) Personality differences explain leadership in barnacle geese. Anim Behav 78:447-453. https://doi.org/10.1016/j.anbehav.2009.06.002

Lamichhane K, Garcia SN, Huggett DB, DeAngelis DL, La Point TW (2014) Exposures to a selective serotonin reuptake inhibitor (SSRI), sertraline hydrochloride, over multiple generations: changes in life history traits in Ceriodaphnia dubia. Ecotox Environ Safe 101:124-130. https://doi.org/10.1016/j.ecoenv. 2013.11.026

Manger P, Li J, Christensen BM, Yoshino TP (1996) Biogenic monoamines in the freshwater snail, Biomphalaria glabrata: influence of infection by the human blood fluke, Schistosoma mansoni. Comp Biochem Phys A 114:227-234. PMID: 8759145

Meredith-Williams M, Carter LJ, Fussell R, Raffaelli D, Ashauer R, Boxall ABA (2012) Uptake and depuration of pharmaceuticals in aquatic invertebrates. Environ Pollut 165:250-258. https://doi. org/10.1016/j.envpol.2011.11.029

Minderman J, Reid JM, Evans PGH, Whittingham MJ (2009) Personality traits in wild starlings: exploration behavior and environmental sensitivity. Behav Ecol 20:830-837. https://doi.org/10. 1093/beheco/arp067

Nagarnaik P, Batt A, Boulanger B (2011) Source characterization of nervous system active pharmaceutical ingredients in healthcare facility wastewaters. J Environ Manag 92:872-877. https://doi. org/10.1016/j.jenvman.2010.10.058

Nentwig G (2007) Effects of pharmaceuticals on aquatic invertebrates. Part II: the antidepressant drug fluoxetine. Arch Environ Con Tox 52:163-170. https://doi.org/10.1007/s00244-005-7190-7

Nyström P, Brönmark C, Granéli W (1999) Influence of an exotic and a native crayfish species on a littoral benthic community. Oikos 85:545-553. https://doi.org/10.2307/3546704

Pavlova GA (2001) Effects of serotonin, dopamine and ergometrine on locomotion in the pulmonate mollusc Helix lucorum. J Exp Biol 204:1625-1633. PMID: 11398751

Péry ARR et al. (2008) Fluoxetine effects assessment on the life cycle of aquatic invertebrates. Chemosphere 73:300-304. https://doi. org/10.1016/j.chemosphere.2008.06.029

Rundle SD, Brönmark C (2001) Inter- and intraspecific trait compensation of defence mechanisms in freshwater snails. Proc R Soc B 268:1463-1468. https://doi.org/10.1098/rspb.2001.1682

Schultz MM, Furlong ET (2008) Trace analysis of antidepressant pharmaceuticals and their select degradates in aquatic matrixes by LC/ESI/MS/MS. Anal Chem 80:1756-1762. https://doi.org/10. $1021 / \mathrm{ac} 702154 \mathrm{e}$

Sidorov AV (2006) Coordination of locomotor activity of mollusc Lymnaea stagnalis at nutrition: role of the internal medium acid-base balance (pH). J Evol Biochem Physiol 42:43-48. https://doi.org/10.1134/s0022093006010066

Silva LJG, Lino CM, Meisel LM, Pena A (2012) Selective serotonin re-uptake inhibitors (SSRIs) in the aquatic environment: an ecopharmacovigilance approach. Sci Total Environ 437:185-195. https://doi.org/10.1016/j.scitotenv.2012.08.021

Silva LJG, Pereira AMPT, Meisel LM, Lino CM, Pena A (2015) Reviewing the serotonin reuptake inhibitors (SSRIs) footprint in the aquatic biota: uptake, bioaccumulation and ecotoxicology. Environ Pollut 197:127-143. https://doi.org/10.1016/j.envpol. 2014.12.002

Stanley JK, Ramirez AJ, Chambliss CK, Brooks BW (2007) Enantiospecific sublethal effects of the antidepressant fluoxetine to a model aquatic vertebrate and invertebrate. Chemosphere 69:9-16. https://doi.org/10.1016/j.chemosphere.2007.04.080 
Styrishave B, Halling-Sørensen B, Ingerslev F (2011) Environmental risk assessment of three selective serotonin reuptake inhibitors in the aquatic environment: a case study including a cocktail scenario. Environ Toxicol Chem 30:254-261. https://doi.org/10.1002/etc.372

Syed N, Winlow W (1989) Morphology and electrophysiology of neurons innervating the ciliated locomotor epithelium of Lymnaea stagnalis (L.). Comp Biochem Phys A 93:633-644

Tain L, Perrot-Minnot M-J, Cézilly F (2006) Altered host behaviour and brain serotonergic activity caused by acanthocephalans: evidence for specificity. Proc R Soc B 273:3039-3045. https:// doi.org/10.1098/rspb.2006.3618

Tierney AJ, Hanzlik KN, Hathaway RM, Powers C, Roy M (2016) Effects of fluoxetine on growth and behavior in the crayfish Orconectes rusticus. Mar Freshw Behav Phy 49:133-145. https:// doi.org/10.1080/10236244.2015.1119974

Turner AM (1996) Freshwater snails alter habitat use in response to predation. Anim Behav 51:747-756. https://doi.org/10.1006/a nbe. 1996.0079

Turner AM, Turner SE, Lappi HM (2006) Learning, memory and predator avoidance by freshwater snails: effects of experience on predator recognition and defensive strategy. Anim Behav 72:1443-1450. https://doi.org/10.1016/j.anbehav.2006.05.010

Valenti TW, Gould GG, Berninger JP, Connors KA, Keele NB, Prosser KN, Brooks BW (2012) Human therapeutic plasma levels of the selective serotonin reuptake inhibitor (SSRI) sertraline decrease serotonin reuptake transporter binding and shelter- seeking behavior in adult male fathead minnows. Environ Sci Technol 46:2427-2435. https://doi.org/10.1021/es204164b

van Harten J (1993) Clinical pharmacokinetics of selective serotonin reuptake inhibitors. Clin Pharmacokinet 24:203-220. https://doi. org/10.2165/00003088-199324030-00003

van Oers K, Klunder M, Drent PJ (2005) Context dependence of personalities: risk-taking behavior in a social and a nonsocial situation. Behav Ecol 16:716-723. https://doi.org/10.1093/ beheco/ari045

Weinberger II J, Klaper R (2014) Environmental concentrations of the selective serotonin reuptake inhibitor fluoxetine impact specific behaviors involved in reproduction, feeding and predator avoidance in the fish Pimephales promelas (fathead minnow). Aquat Toxicol 151:77-83. https://doi.org/10.1016/j.aquatox.2013.10. 012

Werner EE, Peacor SD (2003) A review of trait-mediated indirect interactions in ecological communities. Ecology 84:1083-1100. https://doi.org/10.1890/0012-9658(2003)084[1083:arotii]2.0.co;2

Wilson DS, Clark AB, Coleman K, Dearstyne T (1994) Shyness and boldness in humans and other animals. Trends Ecol Evol 9:442-446. https://doi.org/10.1016/0169-5347(94)90134-1

Wongprasert K, Asuvapongpatana S, Poltana P, Tiensuwan M, Withyachumnarnkul B (2006) Serotonin stimulates ovarian maturation and spawning in the black tiger shrimp Penaeus monodon. Aquaculture 261:1447-1454. https://doi.org/10.1016/j. aquaculture.2006.08.044 